\title{
Abstracts from posters
}

\section{Protein metabolism in burn injury as reflected in the serum urea level G. ARTURSON, T. GROTH, A. HEDLUND and B. ZAAR \\ The Burn Center, University Hospital, and Unit for Biomedical Systems Analysis, Uppsala University, Uppsala, Sweden}

In an attempt to find a more strict relationship between the protein degradation in necrotic tissue and the increase in the serum urea concentration, a computer simulation model has been designed. This model considers, in addition to synthesis, distribution and elimination of urea, various factors affecting the turnover of amino acids, viz intake of dietary protein, intravenous administration of amino acids, net catabolism/ anabolism, and additional degradation of protein by pathological processes. Mathematical analyses of data from patients with severe thermal injuries have been performed on the bases of this conceptual model. An interesting result is the pronounced oscillatory nature of the 'pathological' amino acid inflow rate. Five to seven periods are generally found during the 3 -week period of observation. The same pattern of variability is also seen in different hormone levels. The estimated 'net anabolism' was in the range 6-13 mol $\mathrm{N}$ for the 3-week period, i.e. about $25-60 \mathrm{~g}$ of protein/d, which is equal to nearly twice the normal anabolic rate. The calculated urea appearance rates are in the range $0.5-0.7 \mathrm{~mol}$ urea/d $(1.0-1.4 \mathrm{~mol} \mathrm{~N} / \mathrm{d})$, which corresponds to degradation of about $100 \mathrm{~g}$ protein $/ \mathrm{d}$. The 'net anabolism' closely correlated to a measure of the severity of the thermal injury.

\section{Influence of different parenteral nutrition on post-traumatic lung phospholipid metabolism in the rat}

S. BAHRAMI, H. GASSER, H. REDL, W. STROHMAIER and G. SCHLAG Ludwig Boltzmann Institute for Experimental Traumatology, Vienna, Austria

The ARDS is associated with changes of lung surfactant phospholipid composition. Furthermore, ventilation therapy alters surfactant. Therefore we studied the influence of supportive parenteral nutrition on the composition of phospholipids in lung tissue and lavage fluid.

Three groups of 10 animals (Sprague Dawley 270-300 g) each with the following regimens were compared: (a) carbohydrate + amino acids ( $\mathrm{CH}$ ); (b) carbohydrate + amino acids + lipid emulsion (FAT); (c) carbohydrate + amino acids + lipid emulsion with additional carnitin (CA).

Polytrauma was performed by single femur fracture plus laparotomy with eventeration of intestines for $30 \mathrm{~min}$ and hypovolemia $(2 \mathrm{ml} / 100 \mathrm{~g} \mathrm{bw})$.

After an adaption phase with reduced caloric supply full caloric support was given from the 4 th to the 14 th day $(100 \mathrm{Kcal} / \mathrm{kg} \mathrm{bw} /$ day). The following metabolic parameters were used: N-balance; weight; carnitin in urine; glycogen and triglyceride in the liver; phospholipid total, -classes, -molecular species and fatty acid pattern of lecithin in lung 
tissue and lavage using special HPLC and GC techniques.

We found significantly altered phospholipid patterns in the lung. With lipid emulsior? there was an increased fraction of saturated lecithins (mainly dipalmitoy phosphatidylcholin). In the carnitin group this was even further pronounced. From ouf data we conclude that it is possible to influence surfactant phospholipid composition byo parenteral nutrition with lipid emulsion.

\section{Plasma cortisol and ACTH in the severely injured} R. N. BARTON, H. B. STONER and S. M. WATSON MRC Trauma Unit and Department of Chemical Pathology, Hope Hospital, Salford, UKळ

We previously showed that in recently injured patients plasma cortisol increased with: severity of injury up to an Injury Severity Score (ISS) of around 13, but with more severe injuries the relationship with ISS became negative. We have now measured plasma ACTH in an attempt to explain this phenomenon, which we have been able tog confirm in larger numbers of patients provided samples were taken within $2 \mathrm{~h}$ of injury $\overrightarrow{-}$ Plasma ACTH was very variable in all the injured groups so that some of even the most seriously injured patients had low levels. However, on average it was much higher that in control subjects and it did not show the same tendency as cortisol to decrease at the highest ISS values. These results must be interpreted with caution since the relationship between the two hormones was weak in most groups. Nevertheless the suggest that the lower cortisol concentrations in the most severely injured were at least partly due to a diminished responsiveness of the adrenal cortex to ACTH. Howeväro this phenomenon appeared to be transitory: if samples were taken at later times from patients presenting late, plasma cortisol at ISS values over 13 rose and the biphasio relationship with ISS disappeared.

\section{Hormonal mechanisms of insulin resistance}

P. Q. BESSEY, J. M. WATTERS, P. R. BLACK, D. C. BROOKS, T. T. AOKI and D. W. WILMORE

Harvard University, Brigham and Women's Hospital, Boston MA, USA

To investigate the relationship between insulin resistance and hormonal environmen insulin clamp studies were performed in a variety of hormonal infusion protocols. $\mathrm{A}^{\mathrm{k}}$ primed constant infusion of insulin and a variable rate glucose infusion achieved comparable levels of hyperinsulinaemia and euglycaemia. After glucose and insulin concentrations approached pre-determined levels, whole body glucose disposal and forearm glucose uptake were determined and free fatty acids (FFA) measured. Nine normal men were studied after $72 \mathrm{~h}$ of an infusion of hydrocortisone $(2.3 \mu \mathrm{g} / \mathrm{kg} \mathrm{min}) \widetilde{D}_{0}^{N}$ glucagon ( $3 \mathrm{ng} / \mathrm{kg} \mathrm{min}$ ), and epinephrine ( $30 \mathrm{ng} / \mathrm{kg} \mathrm{min}$ ). Paired studies following $72 \mathrm{hJ}$ of saline infusion served as controls. Additional studies were performed in three of the subjects after $72 \mathrm{~h}$ infusions of hydrocortisone and epinephrine alone. Mean clame values $( \pm$ SEM $)$ are shown $\left({ }^{*} \mathrm{p}<0.05,{ }^{* *} \mathrm{p}<0.01\right)$.

Another series of studies $(\mathrm{N}=5)$ demonstrated reductions in whole body glucoseo 
disposal and forearm uptake during $2 \mathrm{~h}$ epinephrine infusion. Long-term triple hormone and hydrocortisone infusions and short-term epinephrine infusion resulted in marked whole body and peripheral insulin resistance. These studies suggest that epinephrine may mediate insulin resistance early after injury, but that cortisol has the dominant effect later. Furthermore, this effect does not appear to depend on catecholamine induced FFA release.

\begin{tabular}{llcccc}
\hline & & Control & $\begin{array}{c}\text { Triple } \\
\text { Hormone }\end{array}$ & Hydrocortisone & Epinephrine \\
\hline Glucose & $\mathrm{mg} / \mathrm{dl}$ & $92 \pm 1$ & $93 \pm 1$ & 96 & 90 \\
Insulin & $\mu \mathrm{U} / \mathrm{ml}$ & $182 \pm 18$ & $174 \pm 13$ & 181 & 164 \\
FFA & $\mathrm{mEq} / 1$ & $235 \pm 10$ & $193 \pm 15^{*}$ & 212 & 264 \\
$\begin{array}{l}\text { Disposal } \\
\text { Forearm }\end{array}$ & $\mathrm{mg} / \mathrm{kg} \mathrm{min}$ & $8 \cdot 6 \pm 0 \cdot 5$ & $3 \cdot 2 \pm 0 \cdot 5^{* *}$ & $2 \cdot 9$ & $6 \cdot 3$ \\
uptake & $\mathrm{mg} / 100 \mathrm{ml} \mathrm{min}$ & $1 \cdot 0 \pm 0 \cdot 1$ & $0 \cdot 4 \pm 0 \cdot 1^{* *}$ & $0 \cdot 4$ & $0 \cdot 8$ \\
\hline
\end{tabular}

\section{A comparison of continuous feeding and feeding at night only on post-operative oxygen consumption and nitrogen balance I. T. CAMPBELL, R. P. MORTON, S. JUDD and P. M. STELL Liverpool, UK}

It is now common practice in enteral feeding to infuse the feed continuously using gravity or a pump. In a previous study patients fed by 2 -hourly boluses of feed during the daytime alone, had better nitrogen balance and lower oxygen consumption than a group that were fed similar quantities but fed continuously $24 \mathrm{~h}$ a day. Both groups were fed for 5 days after operation for head and neck cancer (1983).

In a further study, oxygen consumption and nitrogen balance were compared in two groups of 9 patients each who were fed enterally similar quantities of Clinifeed iso (Roussel Laboratories Ltd) for five days after major head and neck surgery. Both groups were fed using a pump. One group was fed throughout the $24 \mathrm{~h}$ the other only between $5.00 \mathrm{pm}$ and $9.00 \mathrm{am}$ the following morning. Before operation resting oxygen consumption was the same in both groups. After operation it rose in both groups but was lower in the group fed at night only $(p<0.02)$. Cumulative nitrogen balance over the 5 days in the patients fed continuously was $-0.3+4 \cdot 2 \mathrm{gm}$ (mean \pm SEM) but in those fed at night only was $-19.6 \pm 7.8 \mathrm{gm}(\mathrm{p}<0.05)$. There were no differences between the groups at any stage in blood levels of alanine amino transferase, $\gamma$ glutamyl transferase, alkaline phosphatase or inorganic phosphate.

In the post-operative period feeding at night alone appears to be associated with lower oxygen consumption but poorer nitrogen balance than continuous feeding throughout the $24 \mathrm{~h}$.

\section{REFERENCE}

American fournal of Clinical Nutrition (1983) 38, 870. 
6 A pocket computer program for assessing nutritional requirements of patients

C. M. COLLEY and A. FLECK

Department of Chemical Pathology, Charing Cross Hospital Medical School, London, UK

The accurate assessment of a patient's nutritional needs is obviously desirable to avoi under- or over-feeding. A program has been written for a Sharp PC-1500 pockee computer, which calculates a 'best estimate' of energy and nitrogen requirements for $\cong$ patient. The basal metabolic rate is estimated and modifications are made to this figure to allow for the degree of activity of the patient, various types of trauma, sepsis and pyrexia. Evaluation has shown good correlation between predicted energy requirements and measured metabolic expenditure in normal controls and in a variety of patients] with metabolic rates ranging from $>100 \mathrm{Kcal} /$ day $(4 \cdot 2 \mathrm{MJ} /$ day) to over $3000 \mathrm{Kcal} /$ day $(12.5 \mathrm{MJ} /$ day). Nitrogen requirement is calculated in proportion to the energy, with the ratio varying from $1 \mathrm{~g} \mathrm{~N} / 200 \mathrm{Kcal}$ in reasonably well patients to $1 \mathrm{~g} \mathrm{~N} / 100 \mathrm{Kcal}$ iro severely septic patients. Again a good correlation was found between predicted an $\$$ measured. The program has been used to assess 100 patients under the care of the Charing Cross Hospital Nutrition Team in the course of the past year and has adde greatly to patient care. It is written in BASIC, and may easily be modified to cater fo local conditions. The computer can be used alone, the numbers being read off th $\vec{F}$ liquid-crystal display, or attached to its portable printer, allowing a permanent recor\& to be produced. It is readily portable and thus easy to use at the bedside. We wishog thank Professor H. B. Stoner and Dr R. A. Little of the MRC Trauma Unit, Univerșt of Manchester for providing many of the resting energy expenditure measuremetrts and Sharp (UK) Ltd for the loan of the computer.

7 Glutathione (reduced and oxidized) content of muscle during the course of shock

G. G. CORBUCCI, R. De BLASI, M. G. COOPER* and D. A. JONES* Institute of Anaesthesia and Resuscitation, University of Rome, Italy and ${ }^{*}$ Department of Medicine, University College London, University Street, London, UK

Needle biopsies of muscle from patients with cardiogenic or septic shock were analysee for their content of glutathione (oxidized and reduced). Total cellular glutathionê content decreased during the course of shock, with a change in the ratio of oxidized to reduced glutathione present in the cell. These results suggest that the ability of the celf to remove hydroperoxides is decreased possibly due to changes in the amount of NADPH available to reduce oxidized glutathione formed by the action of glutathion peroxidase (a GSH dependant enzyme involved in the removal of hydroperoxides). 
8 Cellular content of superoxide dismutase and hydroperoxides in muscle from shock patients

G. G. CORBUCCI, C. PISICCHIO, M. B. COOPER* and D. A. JONES*

Institute of Anaesthesia and Resuscitation, University of Rome, Italy and ${ }^{*}$ Department of Medicine, University College London, University Street, London, UK

Muscle needle biopsies were obtained from patients during the course of either cardiogenic or septic shock.

Superoxide dismutase content and hydroperoxide content were determined in homogenates of the muscle. The results show that during the course of shock the cellular superoxide dismutase content falls, either due to inactivation of the enzyme or loss of the enzyme from the cell. Concomitantly there is an apparent increase in cellular hydroperoxide content. The results indicate that during the course of shock the cellular ability to remove oxygen-free radicals (superoxide) is reduced with a resulting increase in hydroperoxide content.

\section{Measurement of plasma $\mathrm{Na}$ and $\mathrm{K}$ concentrations by ion-selective electrodes}

A. K. COVINGTON, C. T. G. FLEAR and S. HAYES

Departments of Physical Chemistry and Clinical Biochemistry and Metabolic Medicine, University of Newcastle-upon-Tyne

Increasingly, plasma $\mathrm{Na}$ and $\mathrm{K}$ concentrations are determined by ion-selective electrodes. Attention has been drawn to underestimation of these concentrations in aqueous solutions when bicarbonate concentration is increased at constant ionic strength (Coleman \& Young, 1981; Czaban et al., 1982; Covington et al., 1984). This could be an important source of error in measurement since bicarbonate concentration in plasma is often low in critically ill patients and rises during treatment. Bicarbonate concentration was varied from $2.5-50 \mathrm{mmol} / 1$ in a 1 in 10 diluting plasma from healthy volunteers; $\mathrm{Na}$ and $\mathrm{K}$ concentrations held constant $(\mathrm{Na}=140 ; \mathrm{K}=4 \mathrm{mmol} / \mathrm{l})$ by adding weighed amounts of dry $\mathrm{Na}$ and $\mathrm{KCl}$. Plasma dilution was tonometered (IL 237) at $37^{\circ} \mathrm{C}$ with $5 \%$ and with $10 \% \mathrm{CO}_{2}$; and $\mathrm{Na}$ and $\mathrm{K}$ concentrations determined using a Corning 902. $\mathrm{pH}$ was measured using 3 blood gas analysers (IL 1302, Corning 165, BMS2Mk2) and $\mathrm{pK}_{1}$ calculated. $\mathrm{pK}_{1}$ is the practical coefficient which interrelates $\mathrm{pH}$, $\mathrm{PCO}_{2}$ and bicarbonate concentration in the Henderson-Hasselbalch equation.

Concentrations of $\mathrm{Na}$ and $\mathrm{K}$ were underestimated as bicarbonate concentration increases. The extent of underestimation was affected by tonometry with $\mathrm{CO}_{2}$. Values for $\mathrm{pK}_{1}$ fell as concentration of bicarbonate increased. 
174 Scientific basis of the care of the critically ill

10 Prediction of outcome in severely septic surgical patients by means sepsis score and factor $B$ plasma level

L. DOMINIONI, R. DIONIGI, V. JEMOS, F. BOBBIO-PALLAVICINI, R? CREMASCHI and A. BALLABIO

Department of Surgery, Sez. Patologia Chirurgica, Policlinico S. Matteo, University of

Pavia, Italy

This study was carried out to control our preliminary observation that patients with severe surgical infections (sepsis score $\geqslant 20$ ) and with complement Factor B (FB) plasma level $<40 \mathrm{mg} / \mathrm{dl}$ would not survive. Seventy surgical ICU patients $(51 \mathrm{M}, 19 \mathrm{~F}$; age $55 \pm 17 \mathrm{SD}$ ) who developed severe septic complications [sepsis score $\geqslant 10$ by the method of Elebute \& Stoner [British fournal of Surgery $(1983) 70,29]$ were studied. A the moment of diagnosis of severe infection their sepsis score was calculated and theif FB plasma level was measured by nephelometry. Thirty patients survived (S) and left ICU after $14 \pm 8$ days; in the 40 non-surviving (NS) patients death occurred $12 \pm 9$ days after the diagnosis of sepsis. The sepsis score was $17 \pm 4$ in $S$ patients and $24 \pm 5$ in N\$o patients $(P<0.001)$. FB plasma level was $47 \pm 13 \mathrm{mg} / \mathrm{dl}$ in $S$ patients and $26 \pm 12 \mathrm{mg} / \mathrm{dP}$ in NS patients $(P<0.001)$. Sepsis score $\geqslant 20$ and $F B<40 \mathrm{mg} / \mathrm{dl}$, alone or irs combination, predicted fatal outcome as follows:

\begin{tabular}{lcccc}
\hline $\begin{array}{l}\text { Predictor of } \\
\text { fatal outcome }\end{array}$ & Patients & $\begin{array}{c}\text { Accuracy } \\
\%\end{array}$ & $\begin{array}{c}\text { Sensitivity } \\
\%\end{array}$ & $\begin{array}{c}\text { Specificity } \\
\%\end{array}$ \\
\hline $\begin{array}{l}\text { (a) Sepsis Score } \geqslant 20 \\
\text { (b) } \mathrm{FB}<40 \mathrm{mg} / \mathrm{dl}\end{array}$ & $(\mathrm{n}=35)$ & 94 & 82 & 93 \\
$(\mathrm{a})+(\mathrm{b})$ & $(\mathrm{n}=40)$ & 77 & 84 & 70 \\
\hline
\end{tabular}

In conclusion, the results confirm that sepsis score $\geqslant 20$ and $\mathrm{FB}<40 \mathrm{mg} / \mathrm{dl}$ are highly accurate, sensitive and specific parameters to predict fatal outcome, occurring $12 \pm 9$ days from the diagnosis of severe sepsis.

\section{Glucose metabolism in human muscle}

${ }^{*} \mathrm{M}$. ELIA, ${ }^{* *} \mathrm{G}$. LIVESEY and * G. NEALE

*Dunn Clinical Nutrition Centre, Addenbrooke's Hospital, Trumpington Street Cambridge and ** ARC Food Research Centre, Colney Lane, Norwich, UK

After injury major changes in the metabolism of glucose are thought to occur in skeletat muscle, the major site of removal of I.V. glucose. However, there is relatively little information about how the metabolism of normal muscle is affected by glucoseo administration. To assess this, arterio-venous concentration differences of variousu metabolites were measured across the forearm muscle beds of six normal subjects before and after glucose administration ( $175 \mathrm{mg} / \mathrm{kg}$ bolus followed by $4 \mathrm{mg} / \mathrm{kg} / \mathrm{min}$ for $60 \mathrm{~min}$ ) Forearm blood flow measurements and indirect calorimetry were performe simultaneously.

Resting energy expenditure increased by a mean of $2 \%$ (N.S.) and respiratory 
quotient from $0 \cdot 76 \pm 0 \cdot 02-0 \cdot 82 \pm 0.02, \mathrm{p}<0.01)$. Arterial blood glucose concentration increased from a mean value of $4.95 \mathrm{mmol} / 1$ to a plateau value of $9.7 \mathrm{mmol} / 1$ and glucose uptake from $500-2800 \mathrm{nmol} / 100 \mathrm{ml} / \mathrm{min}$. The release of glycolytic product decreased (lactate $\mathrm{p}<0.02$; pyruvate $\mathrm{p}<0.01$; alanine $\mathrm{p}<0.01$ ). Total amino acid efflux also decreased. Alanine release was reduced $2 \frac{1}{2}$ fold but glutamine release remained unchanged. Calculations based on these findings suggest that (a) the majority of the glucose taken up by muscle is converted to glycogen; (b) it is unlikely that glucose administration increases Cori or glucose alanine recycling between muscle and liver; (c) glutamine is the major amino acid released by muscle during short-term administration of glucose accounting for $50 \%$ of the total $\mathrm{N}$ release which is fivefold greater than the $\mathrm{N}$ carried out of muscle by alanine.

\section{Effect of non-nutritional factors on muscle function tests}

M. ELIA, S. MARTIN and G. NEALE

Dunn Clinical Nutrition Centre, Old Addenbrooke's Hospital, Trumpington Street, Cambridge, $U K$

Muscle function (maximal momentary grip strength) has been used as an indicator of nutritional status capable of predicting the likelihood of complications after gastrointestinal surgery. The effect of non-nutritional factors on muscle function has not been well documented. Therefore we investigated the changes in grip strength produced by acute infections in otherwise normal individuals $(n=6)$, severe illness (ICU patients $\mathrm{n}=6$ ) and drugs ( $20 \mathrm{mg}$ valium, $40 \mathrm{mg}$ buscopan as used during routine endoscopy $n=6)$. Control data was obtained from 35 adults $(17 \mathrm{~F}, 18 \mathrm{M})$ aged 18-74. Grip strength (dominant side) was directly proportional to creatinine excretion $(r=0.81)$; estimated forearm muscle area $(r=0.73)$ and upper arm muscle area $(r=0.71)$, and lean body mass $(r=0.65)$. Grip strength relative to forearm muscle area decreased with age. Acute infections reduced grip strength by a mean of $35 \%$ and severe illness (ICU patient) by $60 \%$. The intravenous valium and buscopan produced a temporary reduction in grip strength $(50 \%)$ which returned to normal within the next $2 \frac{1}{2} \mathrm{~h}$. These findings contrast with those obtained during short-term starvation (4 days) (no reduction in grip strength $\mathrm{n}=10$ ), and in some subjects with anorexia nervosa.

It is concluded that (a) grip strength in normal subjects correlates with various anthropomorphic indices; (b) in certain clinical circumstances it is not a reliable index of nutritional status.

\section{Arterio-venous oxygen content difference; a method for continuous monitoring \\ T. EMANUEL, R. $M$. TACCHINO, $M$. CASTAGNETO and $G$. C. CASTIGLIONI Dept of Surgery, University of Rome, Italy}

Arterio-venous oxygen content difference is an important parameter in evaluating oxygen transport, tissue oxygen availability and uptake and adequacy of pulmonary oxygenation. 
Standard arteriovenous haemo-gas-analysis is commonly used to compute $\mathrm{C}(\mathrm{a}-\mathrm{v}) \mathrm{O} 2 \frac{\mathrm{a}}{\mathrm{Q}}$ We evaluated the accuracy of oxygen content as calculated with an IL $1302(\mathrm{pH}, \mathrm{pO} 2$ pCO2), an IL 282 oximeter $(\mathrm{Hb}, \mathrm{S} \% \mathrm{O} 2 \mathrm{Hb})$, and an intravascular fibreoptic continuous monitoring oximeter Schwarzer IVH3 (SvO2) in 100 cases.

The oxygen content measured with the three methods showed a very high correlation $(\mathrm{r}=0.9)$. Furthermore, we considered the possibility of estimating $\mathrm{C}(\mathrm{a}-\mathrm{v}) \mathrm{O} 2$ from the $\mathrm{SvO} 2$.

The calculation is based on the assumption that the arterial $\mathrm{Hb}$ is adequatel saturated, and that anyhow great variation of $\mathrm{SaO} 2$ can be predicted by periodic arterial samples or by monitoring end-expiratory gas concentrations.

We conclude that continuous monitoring of $\mathrm{SvO} 2$ by an intravascular device is adequate to estimate $\mathrm{C}(\mathrm{a}-\mathrm{v}) \mathrm{O} 2$.

This simplification is very promising for continuous monitoring of $\mathrm{C}(\mathrm{a}-\mathrm{v}) \mathrm{O} 2$ tha莡. together with VO2 monitoring can provide a complete cardiorespiratory and metabolieu automatic monitoring system.

\section{Hyponatraemia and dilution of body fluids}

C. T. G. Flear and S. W. Roberts

University Department of Clinical Biochemistry and Metabolic Medicine, Royal Victori® Infirmary, Newcastle-upon-Tyne, UK

Malaise, weight loss, fever and hyponatraemia are all gloomy potents in illness. T⿺辶寸 mechanisms have been proposed for non-specific hyponatraemia-syndrome öof inappropriate $\mathrm{ADH}$ secretion (SIADH) and sick cell concept (SCC). SIADH suggeșt water gain reduces $[\mathrm{Na}]_{\mathrm{p}}$ and dilution harms and needs correction. SCC consider hyponatraemia harmless. It should not be corrected. SCC attributes abrupt fall in $[\mathrm{Na}]_{0}^{\circ}$ to isosmotic redistribution of water from leakage of normally non-diffusIble cell solutes? insidious lowering of $[\mathrm{Na}]_{\mathrm{p}}$, to cell inability to sustain normal solute content. Plasm ADH measurements in hyponatraemia do not afford clear evidence of increased secretion. Although higher than expected for reduced osmolality, most ADH levels ar not raised. However, plasma tonicity not osmolality determines ADH release an cannot be measured. Dilution reduces $\left[\mathrm{HCO}_{3}\right]_{\mathrm{p}}$ and ionic strength. Neither are measurable; either increases $\mathrm{pK} /{ }_{1} .\left(\mathrm{pK} /{ }_{1}\right.$ is the practical coefficient interrelating $\mathrm{pH}^{2}$ $\mathrm{PCO}_{2}$ and total $\mathrm{CO}_{2}$ of plasma). For one month we determined $\mathrm{pK} / 1$ values in al plasmas received by the laboratory with $[\mathrm{Na}]_{\mathrm{p}}<130 \mathrm{mmol} / \mathrm{l}(\mathrm{n}=63)$. Mean $\mathrm{pK} / 1=6 \cdot 134^{\circ}$ $\mathrm{SE}=0.0023$. Plasma from 21 healthy volunteers averaged 6.121 $(\mathrm{SE}=0.008)$ ? Adjustment for the defined effect of ionic strength reduction reflected in $[\mathrm{Na}]_{\mathrm{p}}$, makes insignificant the difference obtaining between means $\mathrm{pK}_{1}$ values of these healthy an hyponatraemic plasmas. 
15 Plasma protein changes after injury: conclusions from a simple computer model

A. FLECK, C. M. COLLEY, G. RAINES,* I. McA. LEDINGHAM** and P. WALLACE**

Department of Chemical Pathology, Charing Cross Hospital Medical School, London and Department of Oncology* and Anaesthetics, ** Western Infirmary, Glasgow, UK

The factors which determine the concentration of a plasma protein include:

- The volume and distribution of body fluid

- Microvascular permeability to protein

- Lymphatic return of the protein

- Catabolism

- Synthesis

- Pathological losses

From a simple two-compartment model for albumin distribution and metabolism it can be readily seen that changes in microvascular permeability could produce rapid, significant changes in the plasma concentration of albumin. Transcapillary escape rate (TER) gives a measure of the microvascular permeability to albumin. Significant increases in TER were found to occur within $4 \mathrm{~h}$ of cardiac surgery, in septic shock and in a high proportion of cachectic cancer patients with hypoalbuminaemia.

Our measurements of TER and the synthetic and catabolic rates of albumin in these patients, combined with application of the computer model, show that changes in the rates of synthesis and catabolism are almost insignificant determinants of albumin concentration when compared with changes in microvascular permeability.

16 Synthesis of albumin by patients in septic shock

A. FLECK,* G. RAINES, F. HAWKER and I. Mc.A. LEDINGHAM Departments of Biochemistry and Surgery, Western Infirmary, Glasgow and * Department of Chemical Pathology, Charing Cross Hospital Medical School, London, UK

The synthesis rate of albumin was determined by McFarlane's ${ }^{14} \mathrm{C}$ carbonate method (1963) in 13 patients in septic shock, with serum albumin concentrations from 14-30 g/ 1. The range of absolute synthesis rate (ASR) was $1 \cdot 2-39 \cdot 2 \mathrm{~g} / \mathrm{d}$; (normal range 9-19 g/ d), in two patients it was clearly low: in five patients normal and in six high. No correlation was found between duration or severity of shock and the ASR.

Clearly, in the majority of severely ill patients the fall in albumin concentration is not due to impaired synthesis, and many retain the ability to increase synthesis in response to the decreased concentration.

AF wishes to thank SHERT for financial support (HERT 560).

\section{REFERENCE}

McFarlane A. S. (1963) Measurement of the synthesis rates of liver-produced plasma proteins. Biochemistry fournal 89, 277-90. 
17 The role of catecholamines in acute metabolic and hormonal responses to injury in man

K. N. FRAYN, R. A. LITTLE, P. F. MAYCOCK and H. B. STONER

$M R C$ Trauma Unit, University of Manchester, Manchester, UK

Plasma concentrations of noradrenaline (NA), adrenaline (A) and dopamine (DA) were measured in 40 patients within $4 \mathrm{~h}$ of accidental injury, with Injury Severity Scores (ISS) from 3-50. Concentrations of all 3 amines rose after injury and each correlate® with ISS $(P<0.001)$. The rise in plasma DA was, however, unrelated to ISS per se; 说 was related only to the associated rise in plasma NA. Hyperglycaemia after injury wa $\vec{\odot}$ related to plasma A and not independently to ISS, nor to plasma NA. In contrast

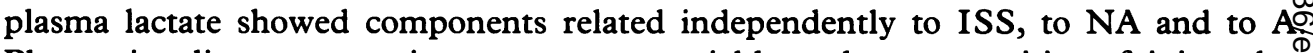
Plasma insulin concentrations were very variable at lower severities of injury bu艼 uniformly low, especially in relation to the hyperglycaemia, at greater severities and this paralleled plasma $A$; in patients with plasma $A>2 \mathrm{nmol} / 1$, the threshold level in. experimental studies for suppression of insulin secretion, insulin levels were $a \mathrm{~A}^{\mathrm{B}}$ $<20 \mathrm{mU} / 1$.

It was concluded that the sympathoadrenal response to injury has a major role in the metabolic changes within the first few hours.

18 Effects of glucocorticoid administration on heart and liver carnitine profiled in fasted rats

T. J. FRENCH, C. J. C. KIRK, M. C. SUGDEN and A. W. GOODE Department of Biochemistry and Surgical Unit, The London Hospital, Whitechate London, UK

Total carnitine concentrations (free + acylated) in hearts and livers from $50 \mathrm{~h}$-starve rats were $1050 \cdot 0 \pm 42.3$ and $510 \cdot 1 \pm 19.5 \mathrm{nmol} / \mathrm{g}$ wet weight respectively $(\mathrm{m}=21)$ Administration of dexamethasone (Decadron; $0.05 \mathrm{mg} / 100 \mathrm{~g}$ body weight; $0 \mathrm{~h}, 24 \mathrm{~h}$ $48 \mathrm{~h})$ increased carnitine concentrations in heart $(1322 \cdot 8 \pm 51.0(\mathrm{n}=4) \mathrm{nmol} / \mathrm{g}$ we weight $(\mathrm{p}<0.001))$ but not in liver $(504.2 \pm 24.3(\mathrm{n}=4) \mathrm{nmol} / \mathrm{g}$ wet weight $)$.

The increase in the heart carnitine content in the dexamethasone-treated rats was predominantly due to a marked increase in the free carnitine concentration from $380 \cdot 4 \pm 26 \cdot 2(\mathrm{n}=21) \mathrm{nmol} / \mathrm{g}$ wet weight $\left(35 \cdot 8 \pm 1 \cdot 5 \%\right.$ of total carnitine) to $660 \cdot 3 \pm 40 \cdot \frac{3}{3}$. $(\mathrm{n}=4) \mathrm{nmol} / \mathrm{g}$ wet weight $(50.0 \pm 2.6 \%$ of total $), \mathrm{p}<0.001)$. Short-chain acylcarnitine concentrations were not significantly different in the control and dexamethasonetreated rats. Long-chain acylcarnitine was decreased $(p<0.01)$ by dexamethasone treatment from $145.9 \pm 8.8(\mathrm{~m}=21) \mathrm{nmol} / \mathrm{g}$ wet weight $(14.0 \pm 0.8 \%$ of total carnitine to $92 \cdot 3 \pm 14 \cdot 4(\mathrm{n}=4) \mathrm{nmol} / \mathrm{g}$ wet weight $(7 \cdot 1 \pm 1 \cdot 3 \%$ of total $)$.

Dexamethasone administration did not significantly affect the concentrations of free or acylated carnitine in the liver although the percent of the carnitine present as free carnitine was slightly increased (from $28.9 \pm 0.8(n=21)$ to $33.3 \pm 1.5(m=4) \%$ of totar. $\mathrm{p}<0.02)$.

The biochemical basis for the increase in free and total carnitine and decrease in long chain acylcarnitine in starved rats treated with dexamethasone has not been established? 
A decrease in the percentage of carnitine present as free carnitine and an increase in the percentage of carnitine present as long-chain acylcarnitine is normally associated with increased fat oxidation: the present findings thus indicate a pertubation in cardiac fat metabolism in the glucocorticoid-treated rats.

19 Inaccuracy of Harris-Benedict formula in weight-losing patients

D. T. HANSELL and J. W. L. DAVIES

University Department of Surgery, Royal Infirmary, Glasgow, UK

The Harris-Benedict (H-B) predictive formula is routinely used to predict resting energy expenditure (REE). Measured REE (MEE) using indirect calorimetry was compared with predicted REE (PEE) using the H-B formula in 35 cancer patients and 24 non-cancer patients. Lean body mass (LBM) was derived from measurements of total body water using a ${ }^{3} \mathrm{H}$ dilution technique.

\begin{tabular}{|c|c|c|c|c|c|}
\hline & \multicolumn{2}{|c|}{ Non-cancer } & \multicolumn{2}{|c|}{ Cancer } & \multirow[b]{2}{*}{$\mathbf{P}$} \\
\hline & mean & $( \pm$ SEM $)$ & mean & $( \pm$ SEM $)$ & \\
\hline Age (years) & $64 \cdot 0$ & $(2 \cdot 6)$ & $65 \cdot 1$ & $(1 \cdot 7)$ & NS \\
\hline Weight (kg) & $62 \cdot 2$ & (3.0) & $62 \cdot 1$ & $(2 \cdot 4)$ & NS \\
\hline Usual weight (kg) & $65 \cdot 2$ & $(3 \cdot 1)$ & $68 \cdot 5$ & $(2 \cdot 2)$ & NS \\
\hline$\%$ usual weight & $\mathbf{9 5 . 4}$ & $(1 \cdot 7)$ & $90 \cdot 2$ & $(1.5)$ & $<0.02$ \\
\hline$\%$ weight loss/month & $1 \cdot 1$ & $(0.5)$ & $2 \cdot 9$ & $(0 \cdot 7)$ & $<0.02$ \\
\hline Surface area $\left(\mathbf{m}^{2}\right)$ & 1.61 & $(0.04)$ & 1.66 & $(0.03)$ & NS \\
\hline LBM (kg) & $48 \cdot 1$ & $(2 \cdot 4)$ & $49 \cdot 8$ & $(2 \cdot 4)$ & NS \\
\hline Watts/kg LBM & 1.36 & $(0.04)$ & 1.36 & $(0.03)$ & NS \\
\hline MEE (as \% PEE) & 103 & $(1 \cdot 5)$ & 109 & $(2 \cdot 2)$ & $<0.02$ \\
\hline MEE (as \% PEE based on usual weight) & 100 & $(1 \cdot 7)$ & 102 & $(2 \cdot 3)$ & NS \\
\hline
\end{tabular}

Although REE expressed in kg LBM is identical in both groups, MEE (as \% PEE) is significantly raised in the cancer group. The cancer patients are significantly more weight-losing, and when usual weight is used in the H-B formula, the apparent hypermetabolism disappears.

The H-B formula underestimates REE in weight-losing patients, thus leading to apparent hypermetabolism. Use of the usual weight gives a more accurate estimate of actual REE.

\section{Energy expenditure in cancer}

D. T. HANSELL and J. W. L. DAVIES

University Department of Surgery, Royal Infirmary, Glasgow, UK

Resting energy expenditure (REE) was measured using indirect calorimetry in 35 cancer patients and 24 non-cancer patients. Lean body mass (LBM) was derived from measurements of total body water using ${ }^{3} \mathrm{H}$ dilution technique. 


\begin{tabular}{|c|c|c|c|c|c|c|}
\hline & \multicolumn{2}{|c|}{ Non-cancer } & \multicolumn{2}{|c|}{ Cancer } & \multirow[b]{2}{*}{$\mathbf{P}$} & \\
\hline & mean & $( \pm$ SEM $)$ & mean & $( \pm$ SEM $)$ & & $\frac{3}{\infty}$ \\
\hline Age (years) & $64 \cdot 0$ & $(2 \cdot 6)$ & $65 \cdot 1$ & $(1 \cdot 7)$ & NS & 7 \\
\hline Weight (kg) & $62 \cdot 2$ & $(3 \cdot 0)$ & $62 \cdot 1$ & $(2 \cdot 4)$ & NS & $\stackrel{\mathscr{O}}{\mathscr{H}}$ \\
\hline Usual weight (kg) & $65 \cdot 2$ & $(3 \cdot 1)$ & 68.5 & $(2 \cdot 2)$ & NS & 읃 \\
\hline$\%$ usual weight & $95 \cdot 4$ & $(1 \cdot 7)$ & $90 \cdot 2$ & $(1 \cdot 5)$ & $<0.02$ & $2 \overline{\bar{\sigma}}$ \\
\hline$\%$ weight loss/month & $1 \cdot 1$ & $(0 \cdot 5)$ & $2 \cdot 9$ & $(0 \cdot 7)$ & $<0.02$ & $2 \stackrel{0}{\frac{1}{1}}$ \\
\hline Mid-arm muscle circ. (\%) & 94 & $(2 \cdot 5)$ & 91 & $(2 \cdot 2)$ & NS & $\stackrel{1}{2}$ \\
\hline Triceps skinfold th. (\%) & 109 & $(8 \cdot 6)$ & 85 & $(7 \cdot 8)$ & $<0.05$ & 5 ڤ్ల \\
\hline Grip strength (\%) & 74 & $(4 \cdot 5)$ & 77 & (3.4) & NS & 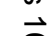 \\
\hline $\mathrm{kg}^{75}$ & $22 \cdot 1$ & $(0.8)$ & $22 \cdot 0$ & $(0.6)$ & NS & \\
\hline Surface area $\left(\mathrm{m}^{2}\right)$ & 1.61 & $(0.04)$ & 1.66 & $(0.03)$ & NS & $\overrightarrow{\vec{\omega}}$ \\
\hline LBM (kg) & $48 \cdot 1$ & $(2 \cdot 4)$ & $49 \cdot 8$ & $(2 \cdot 4)$ & NS & 2 \\
\hline Watts/kg & 1.03 & $(0.03)$ & $1 \cdot 12$ & $(0.03)$ & $<0.05$ & $\frac{10}{3}$ \\
\hline Watts $/ \mathbf{k g}^{75}$ & $2 \cdot 85$ & $(0.07)$ & $3 \cdot 10$ & $(0.07)$ & $<0.005$ & $5 \stackrel{\text { 를. }}{2}$ \\
\hline Watts $/ \mathrm{m}^{2}$ & $38 \cdot 6$ & $(0 \cdot 68)$ & $40 \cdot 7$ & $(0.82)$ & $<0.05$ & $\bar{\omega}$ \\
\hline Watts/kg LBM & $1 \cdot 36$ & $(0.04)$ & 1.36 & $(0.03)$ & NS & $\vec{\nabla}$ \\
\hline
\end{tabular}

There is no difference in REE between cancer and non-cancer patients in terms of $\mathrm{kg}$ LBM, whereas misleading information is derived from expression of REE in terms of $\mathrm{kg}, \mathrm{kg}^{-75}$ and $\mathrm{m}^{2}$. It appears that the weight loss in the cancer group results mainly fron loss of body fat.

\section{Effects of scald injury on hamster cheek pouch ATP-ase}

\section{J. G. HILTON}

Departments of Pharmacology University of Texas Medical Branch and Shriners Bupn Institute, Galveston, Texas, USA

Immediately after thermal trauma, vascular permeability to both water and protein is significantly increased. Using the hamster cheek pouch as an experimental modef Hambrecht and Hilton have reported that scald injury increase in permeability is significantly reduced by pre-treatment with the hydroxyl radical scavenger catalase? These same investigators have reported that lipoxidation generated free-radicals will: significantly inhibit hamster cheek pouch tissue ouabain insensitive ATP-ase. These findings have lead to the postulate that a relationship exists between inhibition of ouabain insensitive ATP-ase and increase in vascular permeability. To test this postulate the effects of scald injury and scald injury after pretreatment with catalase have beere studied. Tissue was obtained from Syrian hamsters anaesthetized with sodium pentobarbital $(60 \mathrm{mg} / \mathrm{kg})$. Scald injury was produced by exposure of one cheek pouch to $100^{\circ} \mathrm{C}$ saline for $10 \mathrm{~s}$. The contralateral untraumatized cheek pouch was used as controfo One series of animals received $32000 \mathrm{IU} / \mathrm{kg}$ of catalase by intravenous injection prior to scald injury. ATPase activity was measured as micromoles of inorganic phosphate formed per mg of protein per hour. The results of this study show that scald injury of the cheek pouch reduced ATP-ase by $32 \%$. In that group of animals pretreated with the hydroxyl radical scavenger catalase, scald injury did not alter ATP-ase. These results suggest that a relationship between the increase in vascular permeability and hydrox radical inhibition of ouabain insensitive ATP-ase. 


\section{Epidural anaesthesia fails to prevent post-traumatic catabolism N. HULTON, D. JOHNSON and D. WILMORE Department of Surgery, Brigham and Women's Hospital, Boston, MA, USA}

Many of the hormonal and metabolic changes which follow lower abdominal surgery are inhibited by epidural anaesthesia. To determine the effect of neurogenic blockade on the protein catabolism associated with injury, 11 dogs underwent general anaesthesia, a standard abdominal operation, and implantation of aortic and venacaval catheters. Six of the animals received a high epidural anaesthetic (T4-S3), started prior to general anaesthesia and maintained continuously for $24 \mathrm{~h}$. Adequacy of blockade was confirmed by neurological assessment and suppression of cortisol rise. Five dogs served as controls. Pre- and post-operative skeletal muscle biopsies were analysed for amino acids and hindquarter amino acid flux measured at 6 and $24 \mathrm{~h}$. Urine was collected for nitrogen analysis. The results for glutamine (GLN), the major amino acid transporting nitrogen from the periphery to the viscera, are shown.

\begin{tabular}{llccc}
\hline & $\begin{array}{c}\text { Urinary N } \\
\mathrm{gm} / \mathrm{kg} / \mathrm{h}\end{array}$ & $\begin{array}{c}\text { GLN flux } \\
\text { at 24 hours } \\
\mathrm{M} / \mathrm{kg} / \mathrm{min}\end{array}$ & $\begin{array}{c}\text { Pre-operative } \\
\text { muscle GLN } \\
\mu \mathrm{M} / \mathrm{L}\end{array}$ & $\begin{array}{c}\text { Post-operative } \\
\text { muscle GLN } \\
\mu \mathrm{M} / \mathrm{L}\end{array}$ \\
\hline Control & $0.49 \pm 0.02$ & $1.71 \pm 0.70$ & $22 \cdot 3 \pm 2.9$ & $16.5 \pm 3 \cdot 6$ \\
Epidural & $0.56 \pm 0.03^{*}$ & $1.55 \pm 0.37^{*}$ & $21 \cdot 4 \pm 2 \cdot 8^{*}$ & $16 \cdot 1 \pm 1^{*}$ \\
\hline
\end{tabular}

* No difference between groups by analysis of variance.

The increased nitrogen excretion, elevated glutamine efflux from the hindquarter, and fall in skeletal muscle glutamine produced by operation were similar in both groups. Protein catabolism following injury is not prevented by epidural blockade, despite inhibition of hormonal responses.

\section{Effects of methylprednisolone on the development of experimental post-traumatic pulmonary microembolism}

\section{JANSSON, B. BÄCKSTRAND, L. RAMMER and S. LENNQUIST}

Department of Surgery and State Institute of Forensic Medicine, University Hospital, Linköping, Sweden

The effects of methylprednisolone on the course of post-traumatic pulmonary microembolism were studied in pigs submitted to a reproducible high-energy trauma of a limb and then observed under long-term anaesthesia. Methylprednisolone sodium succinate $(30 \mathrm{mg} / \mathrm{kg})$, was given to nine pigs one hour after the trauma and thereafter every 8 th $\mathrm{h}$ during a $72-\mathrm{h}$ observation period. Two other groups of pigs were used for comparison, viz 13 traumatized, non-treated and 15 non-traumatized, non-treated pigs. Intrapulmonary microembolism was quantitatively measured by repeated external detection of ${ }^{51} \mathrm{Cr}$-labelled platelets and ${ }^{125} \mathrm{I}$-labelled fibrinogen, sequential chest $\mathrm{X}$-rays and morphologic examination of the lungs post mortem. High-energy musculoskeletal trauma with nonstabilized femoral fracture induced pulmonary microembolism with 


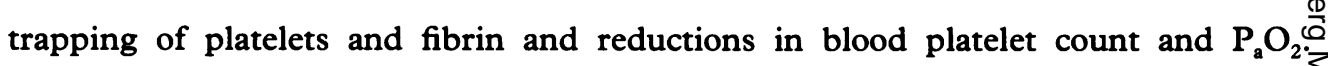
Methylprednisolone delayed the appearance of pulmonary $\mathrm{X}$-ray changes ando modulated $\mathrm{P}_{\mathrm{a}} \mathrm{O}_{2}$ and platelet count reductions, but at the end of the observation periodi the signs of microembolism were as pronounced in this group as in the non-treated? traumatized pigs. Methylprednisolone alone thus did not prevent post-traumatico pulmonary microembolism in this experimental situation.

\section{Influence of the renin-angiotensin system on the sensitivity of the baroreceptor reflex \\ E. KIRKMAN and E. M. SCOTT \\ Department of Physiology, University of Manchester, Manchester, UK}

In cats, anaesthetized with $a$-chloralose $\left(70 \mathrm{mg} \mathrm{kg}^{-1}\right)$ and artificially ventilated, we have investigated the effects of the renin-angiotensin system on the baroreceptor reflex $\overrightarrow{.}$ Baroreceptor sensitivity was assessed in two ways: as the relationship between pressure in a vascularly isolated carotid sinus (CSP) and the reflex effects on blood pressure, mediated by the sympathetic nerves to the heart and blood vessels (Kirkman \& Scott 5 1983) and as the relationship between heart period and a rise in blood pressureo produced by the bolus injection of phenylephrine (4-8 $\mu \mathrm{g} \mathrm{kg}^{-1}$ i.v.) (Smyth et al. 1969) which, in our experiments, describes the vagal cardiac component of the reflex.

Infusion of renin $\left(12 \mathrm{mU} \mathrm{h}^{-1}\right.$ i.v. $)$ significantly increased sensitivity as assessed by either method. The changes were similar to those seen after haemorrhage (Little et 0 1984). Whereas the blockers of the renin-angiotensin system, saralasin (10) $\mathrm{kg}^{-1} \mathrm{~min}^{-1}$ ) and captopril ( $3 \mathrm{mg} \mathrm{kg} \mathrm{kg}^{-1}$ bolus followed by $200 \mu \mathrm{g} \mathrm{kg}^{-1} \mathrm{~h}^{-1}$ i. $\overrightarrow{\mathrm{v}}$. significantly attenuated the reflex response to changes in CSP, particularly to falls, thes drugs did not consistently alter the relationship between heart period and rises in bloofँ pressure.

We are grateful to the British Heart Foundation for financial support.

\section{REFERENCES}

Kirkman E. \& Scott E. M. (1983) fournal of Physiology 342, 73-4.

Little R. A., Randall P. E., Redfern W. S., Stoner H. B. \& Marshall H. W. (1984) Quarterly fournal o $\frac{\mathbb{D}}{B}$. Experimental Physiology (In press).

Smyth H. S., Sleight P. \& Pickering G. W. (1969) Circulation Research 24, 109-21.

25 Effect of tissue injury on the changes in the blood pressure-heart rate reflex produced by haemorrhage, in the rat R. A. LITTLE and H. B. STONER

MRC Trauma Unit, University of Manchester Medical School, Oxford Road Manchester, UK

Moderate haemorrhage $(10-15 \%$ blood volume-1\% body weight) modifies the baroreceptor mediated arterial blood pressure-heart rate reflex in the unanaesthetized rat. The slope of the regression line describing the relationship between heart-period ${ }^{\text {f }}$ 
(HP) and mean arterial blood pressure (MAP), elicited by an infusion of phenylephrine, is increased 10-15 min after haemorrhage with or without displacement to the left (i.e. towards a relative bradycardia). The effect of tissue injury on this response has been studied by testing the acute response to haemorrhage at intervals after the production of bilateral hind-limb ischaemia. If the tourniquets had been in place for $0.5 \mathrm{~h}$ the characteristic changes in the HP-MAP relationship produced by haemorrhage were still found. However, after 2- or 4-h periods of tissue ischaemia the HP-MAP relationship was unaffected by haemorrhage. This abolition of the normal homoeostatic response to haemorrhage by tissue ischaemia may have clinical implications as fluid loss from the circulation is frequently complicated by tissue injury.

\section{Modification of an autonomic component of thermoregulation by injury in man}

R. A. LITTLE, P. RANDALL and H. B. STONER

MRC Trauma Unit, University of Manchester Medical School, Hope Hospital, Salford, $U K$

Core and mean body temperature are reduced soon after multiple injuries in man. It is important to decide whether this is a result of a failure of tissue oxygen transport or to a centrally mediated inhibition of thermoregulation similar to that found after injury in the rat. Recently we have described an inhibition of a behavioural thermoregulatory response in man after mild and moderately severe lower limb injuries (Banks et al., 1983). This study has now been extended to an investigation of changes in forearm blood flow elicited by cooling (immersion in water at $17^{\circ} \mathrm{C}$ ) of the contralateral arm. There is a positive correlation $(r=0.9407 ; p<0.001)$ in control uninjured subjects $(m=33)$ between the reduction in blood flow, which predominantly involves the cutaneous (hand) circulation, and resting flow. Soon $(<6 \mathrm{~h})$ after mild and moderately severe lower limb injuries this relationship is preserved $(r=0.8548 ; n=15 ; p<0.001)$ but the regression line is displaced to the right of the control line with a reduction in slope. Thus at a given resting forearm blood flow the reduction in flow elicited by cooling the contralateral arm is reduced after injury.

\section{REFERENCE}

Banks J. G. et al. (1983) fournal of Physiology 342, 37-8.

27 Disturbed phosphate metabolism and the effect of phosphate supplementation after severe trauma

L. LOVÉN, J. LARSSON, L. LARSSON, H. NORDSTRÖM and S. LENNQUIST Departments of Surgery, Plastic Surgery and Clinical Chemistry, University Hospital, S-581 85 Linköping, Sweden

Severe trauma has been shown to induce disturbance in phosphate metabolism. Since phosphate is of importance for the energy metabolism and the oxygenation of 
tissues, disturbed phosphate metabolism could increase the risk for decreased host $\stackrel{\oplus}{a}$ defence against infection, tissue hypoxia and impaired function of several organ $\frac{3}{0}$ systems.

Forty-six patients with multiple trauma or severe burns were treated with parenteral $\vec{F}$ nutrition containing $3200 \mathrm{Kcal}$ non-protein calories, $14-24 \mathrm{~g}$ protein and $25-75 \mathrm{mmol}$ phosphate per day. With this treatment severe hypophosphataemia was avoided but serum phosphate was decreased the first post trauma week. In skeletal muscle a decrease in inorganic phosphate and high energy phosphates was found. In red cells 2,3-Diphosphoglycerate concentration could be kept normal despite the decreased serum $\nRightarrow$ phosphate during the first post trauma week. This study confirmed that phosphate $\vec{o}$ metabolism is disturbed after severe trauma, and that different tissues have different metabolic reactions during the post trauma period. Phosphate supplementation is one important tool in the metabolic care of severely injured patients, and must always be included in parenteral nutrition programmes.

\section{Pathophysiology of perfluorocarbon emulsions as blood substitutes-} experimental studies in the rat

K. C. LOWE

Department of Zoology, University of Nottingham, UK

Emulsified perfluorocarbons (PFC) have been proposed as resuscitation fluids for hypovolaemic shock and for improving oxygen delivery to ischaemic tissues (Erdman al., 1982; Menasche et al., 1984). Preliminary trials with one preparation, Fluosol-D A. $20 \%$ (F-DA; Green Cross, Japan) have also been performed on humans (Mitsuno et al 1982; Tremper et al., 1982; Nagasawa et al., 1983). In the present study, the effects of isovolaemic exchange-transfusion with either F-DA or the colloidal gelatin preparation, Haemaccel (HL; Hoechst) have been examined in conscious rats. The ability of F-DA or $\mathrm{HL}$ to maintain homeostatic integrity in animals perfused to very low $(<6 \%)$ haematocrits while breathing $80-90 \% \mathrm{O}_{2}$ was evaluated. Heart rate, mean arterial blood pressure and respiration rate remained stable during blood replacement. Significant changes in intravascular fluid composition characterized by hyperkalaemia and hyperuraemia, had occurred at $6 \mathrm{~h}$ after perfusion with F-DA. Mean $( \pm$ s.e.m.) survival times after perfusion with F-DA or HL were: $13 \pm 2 h(n=17)$ and $33 \pm 17 h(n=4)$ respectively. Because of the similarity of animals' survival times following blood replacement with F-DA or $\mathrm{HL}$, it may be concluded that the use of non-oxygencarrying colloids with increased $\mathrm{FiO}_{2}$ might be preferable for use in clinical situations because of problems already encountered in using PFC preparations in vivo (Lowe, 1984).

\section{REFERENCES}

Erdman W. et al. (1982) Injury 14, 70-4.

Lowe K. C. (1984) Pharmacology fournal 232, 73-4/8.

Menasche P. et al. (1984) American fournal of Cardiology 53, 608-13.

Mitsuno T. et al. (1982) Annals of Surgery 195, 60-9.

Nagasawa S. et al. (1983) Neurology Research 5, 19-30.

Tremper K. K. et al. (1982) New England fournal of Medicine 307, 277-83. 
29 Altered myocardial performance in hyperdynamic sepsis

K. H. McDONOUGH, C. H. LANG and J. J. SPITZER

Department of Physiology, Louisiana State University Medical Center, New Orleans, LA, USA

In a high-cardiac output, polymicrobial sepsis model in the rat, whole body $\mathrm{O}_{2}$ consumption, body temperature and heart rate are elevated and mean arterial blood pressure is normal. The in vitro performance of hearts removed from these rats is impaired, i.e. the response of cardiac output (CO) and peak systolic pressure (PSP) to changes in left atrial filling pressure is depressed, as compared to the response of hearts from time-matched control animals. Addition of a cardiac glycoside to the perfusion buffer $\left(10^{-5} \mathrm{M}\right.$ ouabain) improved cardiac performance (CO $\times$ PSP) by an average of $25 \%$ at all filling pressures. Verapamil, at a dose which caused minimal changes in control hearts $\left(10^{-9}\right.$ and $\left.5 \times 10^{-9} \mathrm{M}\right)$, also caused a $20-25 \%$ improvement in CO $\times$ PSP. When work (heart rate $\times$ peak systolic pressure) was held constant, oxidation of exogenous substrates accounted for approximately $100 \%$ of the oxygen consumed by the isolated perfused hearts. Palmitate and glucose oxidation rates were similar to those of time-matched controls. Levels of high energy phosphates and total adenine nucleotides were unaltered in these hearts. Thus the myocardial defect seen in hyperdynamic sepsis seems to be only partly a function of calcium dyshomeostasis and is not associated with inadequate energy supply. Supported by grants GM 32371 and HL07098.

\section{The cardiovascular response to systemic hypoxia in a small mammal:} the rat

J. M. MARSHALL \& J. F. R. PATON

Department of Physiology, The Medical School, Birmingham, UK

In cats and rats anaesthetized with Althesin which does not block transmission through the defence areas, selective carotid chemoreceptor stimulation can evoke the autonomic components of the alerting response (Hilton \& Marshall, 1982; Marshall, 1984). In 20 rats anaesthetized with Althesin 4 levels of systemic hypoxia (breathing 15, 12, 8 or $6 \%$ $\mathrm{O}_{2}$ in $\mathrm{N}_{2}$ for 2-3 min) evoked graded increases in respiratory minute volume (up to $100 \%$ ), and heart-rate (up to $80 \mathrm{bpm}$ ), together with pupillary dilatation, exophthalmos and urination-which are signs of alerting in the conscious animal. Arterial pressure was maintained for the first minute but then fell to as low as $30-40 \mathrm{mmHg}$ with $6 \% \mathrm{O}_{2}$ (when $\mathrm{PaO}_{2}$ was $30-40 \mathrm{mmHg}$ ). After vagotomy $(\mathrm{n}=20)$ or during constant artificial ventilation $(n=14)$ the tachycardia was reduced at a given $\mathrm{PaO}_{2}$ but the arterial pressure response was unchanged. After guanethidine $(n=17)$ or after cutting both sinus nerves $(n=3)$ hypoxia evoked no tachycardia but an immediate fall in arterial pressure. These results imply that chemoreceptor-induced activation of the defence areas is an integral part of the response to systemic hypoxia and that in the rat, the tachycardia of the alerting response is augmented by secondary effects of hyperventilation, while the peripheral vascular components are overcome by local vasodilator effects of tissue 
hypoxia. The young of large animal species also show a pronounced fall in arterial $\frac{\mathbb{\Phi}}{6}$ pressure in hypoxia. We suggest that vasodilator effects of tissue hypoxia are $z$ pronounced in small mammals generally, because their rate of $\mathrm{O}_{2}$ consumption is $\stackrel{\mathbb{Q}}{?}$ decreased in hypoxia (Hill, 1959).

\section{REFERENCES}

Hill J. R. (1959) Yournal of Physiology 149, 346-73.

Hilton S. M. \& Marshall J. M. (1983) Fournal of Physiology 236, 495-513.

Marshall L. J. M. (1984) Fournal of Physiology (in press).

\section{Early changes of the acute phase response- a two stage process} M. A. MYERS, A. FLECK, C. M. COLLEY, B. SAMPSON, B. R. MULLER, A. W. GOODE,* J. BENT** and G. HALL**

Department of Chemical Pathology, Charing Cross Hospital Medical School, London,

* Surgical Unit, The London Hospital, London and ** Department of Anaesthetics, Hammersmith Hospital, London, UK

Increases in plasma concentration of C-reactive protein (CRP), alpha-1-acid $\vec{C}$ glycoprotein (AlAG) and fibrinogen after surgical operation were not detected until $6 \mathrm{~h} \frac{\mathbb{D}}{0}$ after skin incision. Peak concentrations of CRP were reached at $48 \mathrm{~h}$ and of fibrinogen at $\mathbb{D}$ $96 \mathrm{~h}$. AlAG reached its highest concentration at $48 \mathrm{~h}$, and remained at this level until $120 \mathrm{~h}$ after operation. A fall in concentration preceded the increase. Decreases were also seen in albumin, transferrin, iron, zinc and copper, though these remained depresse्ف이 for several days except for copper which increased in concentration at $48 \mathrm{~h}$. The patterns seen are suggestive of at least two mechanisms operating after trauma. The early falls are consistent with a prompt increase in microvascular permeability. The later reductions seen in the binding of iron and zinc to their transport proteins could be produced by the mediator initiating the increase in the acute phase proteins.

\section{Gluconeogenesis in acute and chronic endotoxemia}

J. A. SPITZER, K. M. NELSON and R. E. FISH

Department of Physiology, Louisiana State University Medical Center, New Orleans, LA, $U S A$

Gluconeogenic capability was assessed in hepatocytes isolated from fasted rats $6 \mathrm{~h}$ after i.v. injection of $E$. coli endotoxin $0111: \mathrm{B} 4$ (ET, $3 \mathrm{mg} / 100 \mathrm{~g}$ body weight), or from rats receiving a continuous infusion of $\mathrm{ET}, 0.5-0.6 \mathrm{mg} / 100 \mathrm{~g}$ body weight/day via an implanted osmotic pump. Lactate (LAC), fructose $(\mathrm{F})$, sorbitol $(\mathrm{S})$, dihydroxyacetone (DHA) and glycerol (G) were used as precursors for glucose production. In acute endotoxicosis the rate of gluconeogenesis (GNG) is depressed when the comparison $\Omega$ with control cells is made at identical precursor concentrations. However, this ${ }_{0}$ deficiency can be overcome by mimicking some of the in vivo substrate and hormonal $\mathrm{c}$ conditions. Continuous infusion of ET for $6 \mathrm{~h}$ results in enhanced GNG from LAC, while the extent of stimulation by glucagon and norepinephrine (NE) is blunted $\stackrel{0}{\frac{C}{D}}$ compared with cells of $\mathrm{NaCl}$-infused controls. After $30 \mathrm{~h}$ of $\mathrm{ET}$ infusion $\mathrm{GNG}$ is $\stackrel{\mathscr{P}}{\rightarrow}$ 
depressed, regardless of precursor, compared with food-deprived controls. The response to NE stimulation is below that of controls, although the increment above basal is the same in the two cell populations. The glucagon-induced change is diminished in absolute magnitude and in rise above basal values. Our studies demonstrate that (1) hepatocytes of acutely endotoxic rats are able to match the gluconeogenic rates of control cells if provided with some relevant components of the in vivo milieu, and (2) continuous infusion of a non-lethal dose of ET induces time- and precursor-related adjustments in GNG and responsiveness to hormonal stimulation. Supported by grants GM 30312 and HL07098.

\section{The effects of somatostatin infusion on the metabolic and endocrine response to abdominal surgery}

\section{J. L. PATERSON, G. M. HALL, T. E. ADRIAN* and S. R. BLOOM*}

Departments of Anaesthetics and * Medicine, Royal Postgraduate Medical School, Hammersmith Hospital, London, UK

The role of pancreatic glucagon in mediating the changes in circulating metabolites found during major surgery is unclear. We compared the effects of the infusion of somatostatin $(10 \mu \mathrm{g} / \mathrm{min})$ and the equivalent volume of $150 \mathrm{mmol} / \mathrm{L}$ sodium chloride solution on changes in circulating substrates, glucoregulatory hormones and gut peptides in 12 patients undergoing colonic surgery.

Somatostatin suppressed pancreatic glucagon and insulin secretion during surgery and this was associated with a transient decrease in the hyperglycaemic response to surgery. Lipolysis was augmented in the somatostatin-infused patients, probably secondary to the reduction in insulin secretion. As predicted, circulatory gut peptide values were suppressed by the somatostatin-infusion, but significant differences between the groups were observed only for enteroglucagon and pancreatic polypeptide.

It was noteworthy that pancreatic glucagon values did not increase significantly in the control group of patients. The results suggest, therefore, that basal glucagon concentrations are involved in increasing glucose production during surgery. Furthermore, the failure to demonstrate an increase in circulating values of a hormone during surgery does not mean that the hormone is without metabolic effects.

34 Increased microvascular permeability after injury-an important cause of hypoalbuminaemia

P. POON, G. RAINES,* A. FLECK, I. Mc.A. LEDINGHAM*

Chemical Pathology Department, Charing Cross Hospital Medical School, London, *Western Infirmary, Glasgow, UK

Hypoalbuminaemia is commonly observed in post-operative, septic shock and cachectic cancer patients. Consideration of the factors affecting plasma albumin concentration (body fluid volume and changes in distribution, vascular permeability, lymphatic return, metabolic turnover and losses) led us to use transcapillary escape rate (TER) of albumin as a measure of vascular permeability, since in normal individuals TER of 
albumin is apparently an order of magnitude greater than metabolic turnover.

The TER of albumin was estimated by monitoring the rate of disappearance of a 3 biologically stable radio-iodinated HSA from the plasma during the first hour. Since the? catabolic rate of albumin is about $10 \%$ of the loss to the extravascular spaces, the $\vec{F}$ disappearance rate of the labelled-HSA will closely approximate the rate of the loss tothe tissue spaces. Significantly elevated albumin TER were observed in all patiento groups as summarized below (Mean $\pm 1 S D ; 2 p<0.05)$ :

\begin{tabular}{|c|c|c|c|}
\hline Subject studied & $\mathbf{N}$ & Plasma albumin $(\mathrm{g} / \mathrm{L})$ & Albumin TER $(\% / h)$ \\
\hline Post-cardiac surgery & 15 & $35 \pm 3$ & $12.9 \pm 5.9$ \\
\hline Septic shock & 15 & $25 \pm 4$ & $12 \cdot 4 \pm 4 \cdot 4$ \\
\hline Cachectic cancer & 11 & $26 \pm 4$ & $12 \cdot 8 \pm 6 \cdot 0$ \\
\hline Normals & 10 & $44 \pm 2$ & $5 \cdot 1 \pm 0 \cdot 7$ \\
\hline
\end{tabular}

Elevated albumin TER observed in these patients suggests that elevated microvascularo permeability might be a major determinant in hypoalbuminaemia.

35 The defence areas of the brain-stem: central integrative synapses and 3 neural pathways involved in the cardiovascular response to injury W. S. REDFERN, L. MARSON and S. M. HILTON

Department of Physiology, The Medical School, University of Birmingham, UK

There is good evidence that the defence reaction plays a key role in the cardiovascular response to injury, being triggered by afferent neural inputs. The pattern of cardiovascular changes characteristic of the defence reaction includes an increase in blood pressure and heart rate, with a dilatation in muscle vascular beds and vaso- $\Rightarrow$ constriction in renal and other beds. We have begun to uncover the synaptic regions of 3 the rat brain-stem which integrate this pattern of response, and their interconnections, using two complementary techniques. In rats anaesthetized with alphaxalonealphadolone, micro-injections of the synaptic excitant D,L-homocysteic acid (DLH; $3 \mu \mathrm{g}$ in $0 \cdot 1 \mu \mathrm{l}$ ) into the dorsal periaqueductal grey matter (D-PAG) produced the pattern: of response outlined above. The same characteristic pattern, but without renal 3 . vasoconstriction, was evoked by DLH from three other areas, viz a small area dorsal too̊ the optic chiasm (DOC), an area encompassing part of the dorsomedial hypothalamic nucleus (DMH) and an area medial to the lateral lemniscus (MLL) in the pons. $\frac{}{5}$ Injections of DLH into a restricted area of the ventral medulla (VM) lateral to the inferior olives produced the pattern of response except that there was vasoconstriction in the muscle bed. In order to study the interconnections of these areas, the retrograde $O$ neuronal tracing agent horseradish peroxidase was iontophoresed into several of these 0 sites and into the spinal cord in separate experiments. Histological analysis showed that both DOC and DMH project to D-PAG and that D-PAG and MLL project to VM, which in turn provides a major input to the pre-ganglionic sympathetic cell bodies in the spinal cord. The identity of the neurotransmitters involved is being investigated. $\stackrel{\mathbb{D}}{\rightarrow}$ 
36 The effect of neonatal capsaicin on the blood pressure response to limb ischaemia in the rat

H. B. STONER and H. W. MARSHALL

MRC Trauma Unit, Stopford Building, Manchester University, Oxford Road, Manchester, UK

It has been suggested (Redfern et al., 1984) that the afferent impulses from ischaemic muscle which interfere with homeostatic cardiovascular reflexes are carried to the spinal cord by C-fibres. Tests of this possibility were carried out on young adult male rats which had been anaesthetized with halothane at 2 days old and injected with either $50 \mathrm{mg}$ capsaicin $/ \mathrm{kg}$ I.P. or an equivalent volume $(0.01 \mathrm{ml} / \mathrm{g} \mathrm{BW})$ of vehicle (Wall, 1982). When they weighed between $196-240 \mathrm{~g}$ they were anaesthetized with urethane $(1.5 \mathrm{~g} / \mathrm{kg}$ $\mathrm{BW}$ ), the blood pressure recorded from the ventral tail artery and they were placed in a $30^{\circ} \mathrm{C}$ environment. After $90 \mathrm{~min}$ bilateral hind-limb tourniquets were applied and the blood pressure rose to reach a maximum after $30 \pm 2 \mathrm{~min}$ in the 9 capsaicin-treated rats and after $27 \pm 3 \mathrm{~min}$ in the vehicle-treated rats. The rise in pressure was $24 \pm 2 \mathrm{mmHg}$ in the former and $49 \pm 2 \mathrm{mmHg}$ in the latter $(P<0.001)$. As the majority of the C-fibres would have been eliminated in the capsaicin-treated rats this difference in the pressure change suggests that $\mathrm{C}$-fibres are concerned in the rise in blood pressure produced by ischaemic muscle.

\section{REFERENCES}

Redfern W. S., Little R. A., Stoner H. B. \& Marshall H. W. (1984) Quarterly Fournal of Experimental Physiology (in press).

Wall P. D. (1982) fournal of Physiology 329, 21-35.

37 The mechanism of the pulmonary oedema of smoke inhalation

D. TRABER, G. SCHLAG, H. REDL and L. TRABER

Ludwig Boltzmann Institute for Experimental Traumatology, Vienna, Austria and University of Texas Medical Branch $\mathcal{E}$ Shriner's Burns Institute, Galveston, Texas, USA

We studied smoke inhalation in sheep which were prepared for study by staged surgical procedures in which catheters were implanted for chronic measurement of cardiopulmonary variables including lung lymph flow. The animals were studied in the unanaesthetized state then anaesthetized with halothane and smoke from burning cotton was insufflated into them with a bee smoker. Anaesthesia was discontinued and variables were measured for $72 \mathrm{~h}$. The $\mathrm{PaO}_{2}$ gradually fell to values less than $60 \mathrm{mmHg}$ by $12 \mathrm{~h}$. At that time the animals were placed on a ventilator. There was a gradual increase in lung lymph flow (LQ) which reached a plateau at $24 \mathrm{~h}$ post-injury. This rise in LQ was associated with an elevation in the lymph to plasma protein concentration ratio $(\mathrm{L} / \mathrm{P})$. There was also an elevation in extravascular lung $\mathrm{H}_{2} \mathrm{O}\left(\mathrm{EV} \mathrm{H}_{2} \mathrm{O}\right)$. Lung converting enzyme (LCE), an index of pulmonary capillary endothelial damage and Bglucuronidase (BG) was also increased. It is concluded that smoke inhalation causes a release of proteolytic enzymes that produce microvascular endothelial damage and pulmonary oedema as a consequence of the increased permeability to protein. 
38 Intramuscular concentrations of glutamine and high-energy phosphates in septic and malnourished patients

J. C. TRESADERN and C. J. THRELFALL

University Department of Surgery and MRC Trauma Unit, Hope Hospital, Salford, UK $\stackrel{\overrightarrow{\mathrm{F}}}{\mathrm{g}}$

A study was made of the changes in intramuscular concentrations of glutamine and the $\frac{\bar{\sigma}}{\bar{c}}$ high-energy phosphates in patients with malnutrition, with and without sepsis. $\vec{\nabla}$ Relationships were studied between these and other biochemical variables (lactate, $\frac{\circ}{\mathrm{N}}$ pyruvate and glycogen) and some indices of nutrition and sepsis.

The concentrations of high-energy phosphates and of total adenine nucleotides were $\overrightarrow{0}$ depressed in both septic and non-septic malnourished patients. The changes were more $\vec{\omega}$ marked in the septic than in the non-septic group, although both groups of patients had similar degrees of muscle wasting. However, there was no significant relationship $\exists$ between the concentrations of high-energy phosphates and the indices of nutrition and $\vec{\omega}$ sepsis used in this study.

Intramuscular concentrations of glutamine and its precursor, glutamate, were ${ }^{\circ}$ depressed only in the septic group of patients. There was no significant relationship 9 between the concentrations of these two metabolites, nor between the concentrations of $\vec{\rho}$ glutamine and the high-energy phosphates. The reduction in glutamine concentrations $\frac{\pi}{0}$ seen in the septic group was therefore unlikely to be a result of deficiencies in the supply of energy or of the precursor, glutamate.

39 Effect of splanchnic nerve blockade on endocrine-metabolic response abdominal surgery

H. TSUJI, T. ASOH and C. SHIRASAKA

Department of Surgery, Medical Institute of Bioregulation, Kyushu University, Beppu, fapan

In order to elucidate the role of sympathetic nerves in endocrine-metabolic response to abdominal surgery, the splanchnic nerves were blocked intraoperatively in patients undergoing elective gastrectomy with general anaesthesia. Also, endocrine-metabolic $\stackrel{0}{-}$ responses were compared between patients receiving gastrectomy with either general anaesthesia or epidural analgesia.

Rises in plasma ACTH, cortisol, glucose and FFA were significantly less in patients 3 receiving splanchnic blockade than those with general anaesthesia alone. Urinaryo excretion of catecholamines was also reduced significantly by splanchnic nerve $₹$ blocikade. The inhibitory effect of splanchnic nerve blockade on the endocrine- $\rho$ metabolic responses was almost identical with that of epidural blockade.

The results suggested that the known effect of epidural analgesia inhibiting endocrine-metabolic response to surgery is mainly due to sympathetic nerve blockade. $\stackrel{O}{\circ}$ The sympathetic nerves are thus considered to be playing a principal role in eliciting $\tilde{O}$ these stress responses. Since these stress responses can be safely inhibited with either $\tilde{N}$ epidural or splanchnic blockade, it was suggested that most of these responses are unnecessary and may only be obligatory responses to sympathetic nerve stimulation. 
40 Epidural analgesia in upper abdominal surgery

H. TSUJI, T. ASOH and C. SHIRASAKA

Department of Surgery, Medical Institute of Bioregulation, Kyushu University, Beppu, fapan

The inhibitory effect of epidural blockade on endocrine-metabolic response to surgery has been well documented and its beneficial effect in surgery has been suggested. Clinically, however, substantial advantage of epidural analgesia over general anaesthesia has only been reported in lower abdominal surgery. This presentation demonstrates our experience with epidural analgesia employed as a sole anaesthetic technique in upper abdominal major surgery.

Three hundred and fifty patients were operated on under continuous epidural analgesia. Operative procedures included 95 gastrectomies, 90 cholecystectomies and 6 pancreaticoduodenectomies. Intraoperatively, epidural analgesia provided satisfactory anaesthesia and all patients did quite well during and after procedures. Peroperatively, endocrine-metabolic responses were significantly inhibited in these patients compared with those receiving general anaesthesia.

Post-operatively, the patients receiving epidural analgesia were more active, less distressed and had significantly lower incidence of pulmonary complications than those receiving general anaesthesia.

The results indicated that epidural analgesia was not only possible but rather preferable for upper abdominal surgery. These results may be associated with an inhibited stress reaction to surgery.

\section{Glucose utilization in septic surgical patients studied by the hyperglycaemic glucose clamp technique}

R. H. WHITE,* K. N. FRAYN, R. A. LITTLE, C. J. THRELFALL and M. H. IRVING*

* Department of Surgery and MRC Trauma Unit, Hope Hospital (University of Manchester School of Medicine), Salford, UK

We have compared the metabolic responses of 10 septic patients and 9 normal controls to a controlled glucose load using the hyperglycaemic glucose clamp technique (DeFronzo et al., 1979) in which the plasma glucose concentration is raised to and maintained at $12 \mathrm{mmol} / 1$ for $2 \mathrm{~h}$. Glucose utilization in the septic patients, assessed by the amount infused to maintain a constant concentration, was significantly depressed $(27 \pm 3 \mathrm{SEM}$ vs $50 \pm 5 \mu \mathrm{mol} / \mathrm{kg} / \mathrm{min}, \mathrm{p}<0.001)$ despite a normal insulin response $(91 \pm 17$ vs $74 \pm 13 \mathrm{mU} / 1, \mathrm{p}>0 \cdot 25)$. Results are for last $20 \mathrm{~min}$ of the infusion. Plasma noradrenaline concentrations were higher in the septic patients throughout the test, but showed no response to glucose infusion in either group (baseline values $3.3 \pm 0.8$ vs $0.8 \pm 0.1 \mathrm{nmol} / \mathrm{l}, \mathrm{p}<0.002$; finai values $2.9 \pm 0.7$ vs $0.8 \pm 0.1 \mathrm{nmol} / 1, \mathrm{p}<0.005)$. Plasma adrenaline showed no significant differences between the groups. Plasma free fatty acid concentrations were similar initially (0.58 $\pm 0.04 \mathrm{vs} 0.63 \pm 0.10 \mathrm{mmol} / 1$ in controls) and 
192 Scientific basis of the care of the critically ill

fell in both groups during glucose infusion (final values $0.20 \pm 0.03$ vs $0.23 \pm 0.05 \mathrm{mmol} / \frac{3}{8}$ 1).

The impairment of glucose utilization in sepsis thus results neither from impaired insulin secretion nor from an elevated plasma free fatty acid concentration.

REFERENCE

DeFronzo et al. (1979) Am. F. Physiol. 237, E214-E223.

42 The pathological mechanisms of neuroendocrinal regulation and metabolism in shock

V. N. YELSKY, R. A. SAMSONENKO, A. A. NIKONOVA, T. E. MAREYEVA, A

K. MANANKOV, Y. Y. KRYUK and E. D. YAKUBENKO

Donetsk, Medical Institute, USSR

The phase character of the hypothalamic-hypophyseal-adrenal system (HHAS functioning was established. The mechanisms of central link activation in the system regulation were revealed: the role of corticotrophinliberin adrenoglomerulotrophin, the changes of feedback; the significance of monoamines, $a$ - and $\beta$-adrenoreceptors, $M \frac{\mathbb{0}}{\frac{0}{0}}$ serotonin, dopamine, $\mathrm{H}_{1} \mathrm{H}_{2}$-histamine, central $\mathrm{M}$-cholinoreceptors, polyamines and neuropeptides, $\gamma$-aminobutyric acid and opioid structures in the HHAS activation wer@ estimated. The peculiarity of gluco- and mineralocorticoid biosynthesis, thgite distribution in the tissues, the influence of catecholamines, serotonin, histamine 8 n metabolism, the content of biogenic amines and that of precursors, monodiaminoxidase activity of mitochondria were determined. The influence corticosteroids and biogenic amines on the mitochondrial enzyme activity of energyo metabolism (LDH, SDH, ATP-ase) was noted. The intracellular membrang disturbances were accompanied by an increased activity of lysosomic enzymes (cathepsin $\mathrm{D}, \mathrm{RN}$-ase, $\mathrm{DN}$-ase, $\mathrm{AP}$-ase) and extended content of total lipoids triglycerides and the products of their peroxide oxidation. The metabolic changes were adaptationally directed, but economy and rationality being improper in shock (sic). 